\title{
Operant eyeblink conditioning without awareness: A preliminary report
}

\author{
J. D. Keehn, K. E. Woyd, Mary Hibbs and Diane Johnson \\ WASHINGTON STATE UNIVERSITY
}

\begin{abstract}
Abstraet
Ss were instructed that pennies could be earned for lever pressing. After a while lever presses were made non-functional and pennies were earned for eyeblinks according to DRL and FR schedules. The Ss never became aware of this change and lever pressing rates remained high. Blink rates of all Ss changed to conform with the reinforcement schedules.
\end{abstract}

\section{Problem}

According to the Law of Reinforcement, a response increases in strength if it is followed immediately by a reinforcing state of affairs. The Law refers only to a temporal contingency and does not require that the response produce the reinforcer, or that the contingency be apprehended (Skinner, 1963). Although clinical and anecdotal examples of behavior that could be accounted for by the Law are common enough, they are usually explained in other ways, and convincing laboratory demonstrations of the full implications of the Law are exceedingly rare (Hefferline \& Keenan, 1963). Verbal conditioning that once seemed to demonstrate unconscious learning through reinforcement in humans (Greenspoon, 1955; Krasner, 1958) is now thought to depend upon cognition (Spielberger, 1962; DeNike, 1964). We chose eyeblinking as a possible response to modify through reinforcement, and used another response as an objective indicator of awareness.

\section{Method}

Four female college students served as Ss. The experimental room contained a table and chair placed beside a one-way mirror so that Ss' eyeblinks could be observed by E. A response lever, a panel light, a counter and a button switch were on the table. A buzzer was mounted below the lever. The Ss were told that pressing the lever would produce points on the counter, and that they would be paid one cent for each point earned in a session. Whenever the counter stepped the light came on and the buzzer sounded. The S was instructed to terminate them by pressing the button switch before resuming responding. At the beginning of Session 1, E activated the counter contingent upon high response rates, and when performance stabilized the counter was activated according to VR reinforcement schedules programmed automatically by commercial relay equipment located two rooms away from the experimental room.

In the first few sessions operant eyeblink levels were determined by practised $\mathrm{Es}_{0}{ }^{2}$ Each $\mathrm{E}$ observed an $\mathrm{S}$ through the one-way mirror and pressed a key whenever $\mathrm{S}$ blinked. Blinks and lever presses were recorded on

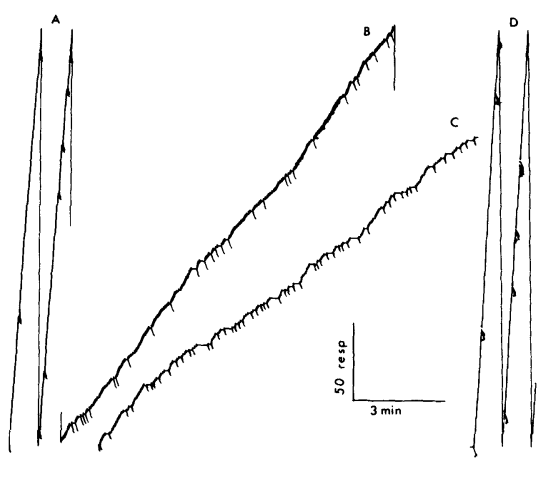

Fig. 1. Cumulative lever press $(A, D$,$) and blink (B, C)$ records of $S$ $\mathrm{AL}$ on the first $(\mathrm{A}, \mathrm{B})$ and final $(\mathrm{C}, \mathrm{D})$ sessions with eyeblinking reinforced on schedule DRL $4 \mathrm{sec}$. Lever presses were non-functional.

separate cumulative recorders, and reinforcements were presented automatically. At first reinforcements were delivered for lever pressing according to schedules ranging from VR 50 to VR 150 , but after 3 sessions lever presses became non-functional and reinforcements were made contingent upon eyeblinking. One $\mathrm{S}$ (AL) was run for 5 sessions with eyeblinks reinforced on schedule DRL 5 sec., followed by 8 sessions on reinforcement schedule DRL $4 \mathrm{sec}$. The other three Ss were reinforced for eyeblinking on various FR and DRL schedules.

\section{Results}

The reinforcement schedules exerted control over the eyeblinking patterns of all four Ss, while lever pressing continued even though it was non-functional. Figure 1 shows typical portions of lever pressing and blinking response records for the first $(A, B)$ and final $D, C$ ) sessions on which $S A L$ was reinforced for blinking on schedule DRL $4 \mathrm{sec}$. The lever pressing rate averaged about 300 per min. for each session while the rate of eyeblinking fell from 24 to 16 responses per min. on the average over these sessions. This fall in blink rate came about through an increase in the percentage of inter-response times greater than $4 \mathrm{sec}$. from 10.25 to 30.0 , which in turn increased the density of reinforcements from 2.68 to 4.59 per min. over the 8 sessions. That is, with reinforcements scheduled for eyeblinking on DRL $4 \mathrm{sec}$. S came to adjust her blink rate toward this schedule.

Figure 2 shows cumulative eyeblink records of S VT on her third and final operant level session, and on Session 4 when eyeblinks were reinforced on schedule FR 8. The response rate of ratio reinforced blinks is 


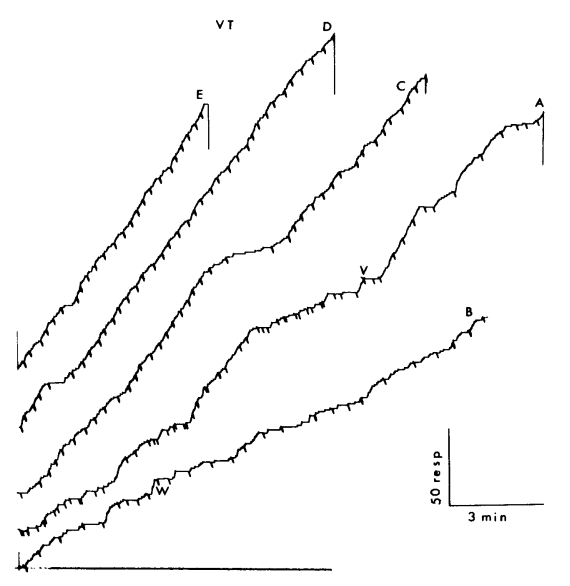

Fig. 2. Records A and B are operant eyeblink rates of S VT with reinforcements delivered for lever pressing on VR 50 (up to V), VR 100 ( V to W) and VR 150 in Session 3. Records C, D and E are eyeblink records from Session 4 when blinking was reinforced on FR 8 throughout.

appreciably higher than operant performance, although the unreinforced blink rates shown in the figure are the highest recorded in the operant level sessions. Figure 3 shows the transition from the low operant level of unreinforced eyeblinks on Session 3 for $\mathrm{S} \mathrm{KD}$, when $78 \%$ of the inter-response times exceeded $4 \mathrm{sec}$. to the accelerating rate in Session 4 when all inter-response times above $2 \mathrm{sec}$. (DRL $2 \mathrm{sec}$.) were reinforced.

\section{Discussion}

Whenever reinforcement occurs $\mathrm{S}$ is emitting many responses. If the Law of Reinforcement requires only a temporal contingency then all of these responses (except some that may be excluded by certain criteria; Kimble, 1964) must become conditioned. In the present study both lever presses and eyeblinks were controlled by reinforcements first programmed to establish high pressing rates, and later programmed for eyeblinks alone.

Normally $\mathrm{E}$ is concerned only with the response that effectively produces reinforcement, and awareness is assessed according to S's verbalizations about the relationship between reinforcement and this response. But these verbalizations are themselves conditioned by the reinforcement contingency, and the assumption that the effective response cannot be conditioned until the verbal response is learned may be false. Our study suggests

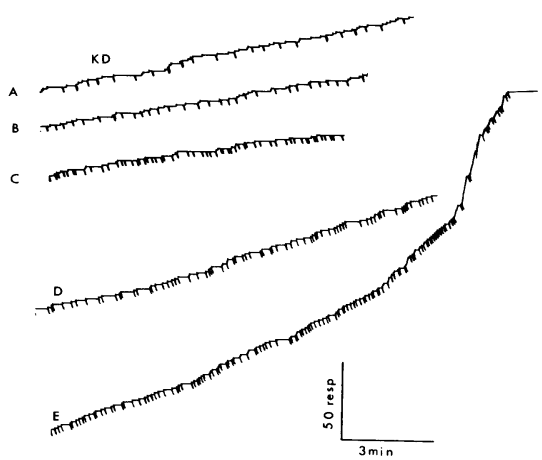

Fig. 3. Records A, B and C are S KD's operant eyeblink rates when reinforcements were scheduled for lever pressing on VR 150, VR 100 and VR 50, respectively. Records $\mathrm{D}$ and $\mathrm{E}$ are from the following session when eyeblinks were reinforced on schedule DRL $2 \mathrm{sec}$.

that it is, because verbal behavior was never conditioned in relation to eyeblinks. It undoubtedly was conditioned to lever pressing, and this may have decreased the probability of it becoming conditioned to blinking.

\section{References}

DeNIKE, L. D. The temporal relationship between awareness and performance in verbal conditioning. J. exp. Psychol., 1964, 68, 521-529.

GREENSPOON, J. The reinforcing effect of two spoken sounds on the frequency of two responses. Amer. J. Psychol., 1955, 68, 409-416. HEFFERLINE, R. F., \& KEENAN, B. Amplitude induction gradient of a small scale (covert) operant. J. exp. Anal. Behav., 1963, 6, 307-315.

KIMBLE, G. A. Categories of learning and the problem of definition. In A. W. Melton (Ed.), Categories of human learning. New York: Academic Press, 1964.

KRASNER, L. Studies of the conditioning of verbal behavior. Psychol. Bull., 1958, 15, 148-171.

SKINNER, B。F。Operant behavior. Amer. Psychologist, 1963, 18, 503-515.

SPIELBERGER, C.D. The role of awareness in verbal conditioning. J. Pers., 1962, 30, 73-101.

\section{Notes}

1. This research was supported in part by USPHS Grant No. MH-08461 and in part by a grant from the Washington State University Research Fund.

2. Data on S AL were collected by Miss Diane Johnson; those on the other Ss by Miss Mary Hibbs. Mr. Al Dobbs and Miss Rae Larson assisted in establishing experimenter reliability. 